\title{
Genome-wide blood DNA methylation alterations at regulatory elements and heterochromatic regions in monozygotic twins discordant for obesity and liver fat
}

\author{
Miina Ollikainen ${ }^{1 *}$, Khadeeja Ismail ${ }^{1}$, Kristina Gervin², Anjuska Kyllönen ${ }^{3}$, Antti Hakkarainen ${ }^{4}$, Jesper Lundbom ${ }^{4}$ \\ Elina A Järvinen ${ }^{3}$, Jennifer R Harris ${ }^{5}$, Nina Lundbom ${ }^{4}$, Aila Rissanen ${ }^{6,7}$, Robert Lyle ${ }^{2}$, Kirsi H Pietiläinen 3,7,8† \\ and Jaakko Kaprio ${ }^{1,8,9+}$
}

\begin{abstract}
Background: The current epidemic of obesity and associated diseases calls for swift actions to better understand the mechanisms by which genetics and environmental factors affect metabolic health in humans. Monozygotic (MZ) twin pairs showing discordance for obesity suggest that epigenetic influences represent one such mechanism. We studied genome-wide leukocyte DNA methylation variation in 30 clinically healthy young adult MZ twin pairs discordant for body mass index (BMl; average within-pair BMl difference: $5.4 \pm 2.0 \mathrm{~kg} / \mathrm{m}^{2}$ ).

Results: There were no differentially methylated cytosine-guanine $(\mathrm{CpG})$ sites between the co-twins discordant for BMI. However, stratification of the twin pairs based on the level of liver fat accumulation revealed two epigenetically highly different groups. Significant DNA methylation differences ( $n=1,236 \mathrm{CpG}$ sites (CpGs)) between the co-twins were only observed if the heavier co-twins had excessive liver fat ( $n=13$ twin pairs). This unhealthy pattern of obesity was coupled with insulin resistance and low-grade inflammation. The differentially methylated CpGs included 23 genes known to be associated with obesity, liver fat, type 2 diabetes mellitus (T2DM) and metabolic syndrome, and potential novel metabolic genes. Differentially methylated $\mathrm{CpG}$ sites were overrepresented at promoters, insulators, and heterochromatic and repressed regions. Based on predictions by overlapping histone marks, repressed and weakly transcribed sites were significantly more often hypomethylated, whereas sites with strong enhancers and active promoters were hypermethylated. Further, significant clustering of differentially methylated genes in vitamin, amino acid, fatty acid, sulfur, and renin-angiotensin metabolism pathways was observed.
\end{abstract}

Conclusions: The methylome in leukocytes is altered in obesity associated with metabolic disturbances, and our findings indicate several novel candidate genes and pathways in obesity and obesity-related complications.

Keywords: DNA methylation, Epigenetics, Monozygotic twins, Obesity, Liver fat

\section{Background}

Obesity is associated with an increased risk for metabolic disorders, in particular type 2 diabetes mellitus (T2DM). However, the rate at which metabolic disturbances become clinically apparent varies. Approximately $30 \%$ of obese individuals appear metabolically healthy

\footnotetext{
* Correspondence: miina.ollikainen@helsinki.fi

${ }^{\dagger}$ Equal contributors

'Department of Public Health, University of Helsinki, Helsinki, Finland

Full list of author information is available at the end of the article
}

[1]. These individuals are insulin sensitive and have normal liver fat and visceral fat content, and their adipose tissue remains free of inflammation and mitochondrial dysfunction $[1,2]$. The causes of the variability in healthrelated responses to excess weight are poorly understood. Some of the variation may be due to genetic background, lifestyle, and other environmental factors. The development of high levels of liver fat predicts other metabolic complications, and nonalcoholic fatty liver disease is closely associated with obesity in many, but not all obese

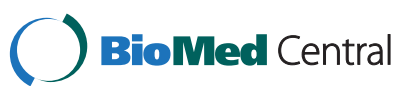


individuals [3]. However, the genetic and environmental factors are difficult to disentangle, and joint genetic and environmental processes underlying the development of metabolic consequences of obesity have not been studied.

Epigenetics, as a potential link between environmental exposures and gene activity, is an ideal approach to unravel the complex etiology of obesity and related comorbidities [4]. As epigenetic mechanisms react to different environmental factors, including nutrients [5-7], environmental components (such as chemicals, for example, from tobacco [8-10]), and metabolic states [11-13], in a tissue-specific manner, epigenetic studies may especially benefit characterization of early disease progression.

Despite the large number of epigenetic studies of obesity and metabolic diseases using animal models, there are few epigenetic studies of obesity in humans. Most of the human studies have explored the DNA methylation status of a few previously identified genes known to affect obesity $[7,14,15]$ or obesity-associated traits [16]. To identify novel genes and pathways related to obesity and obesityinduced complications, hypothesis-generating epigenomewide association studies (EWAS) are needed. Two previous studies using the HumanMethylation27 BeadChip with 27,000 cytosine-guanine sites (CpGs), primarily targeting gene promoters and $\mathrm{CpG}$ islands (CGIs), examined blood leukocytes of obese and lean adolescents $[17,18]$. Wang et al. [6] discovered two obesity-associated inflammatory genes (UBASH3A and TRIM3), and Almen et al. [18] identified $20 \mathrm{CpGs}$ differentially methylated between the groups. A larger study looking at the impact of body mass index (BMI) on DNA methylation in different tissues using the HumanMethylation 450 BeadChip by Dick et al. found five probes correlated with BMI, three of which were in the intron of HIF3A [19]. Recent papers also show that specific DNA methylation profiles in blood [20] and liver [21] may provide a link between aging and obesity. None of the obesity-associated CpGs were common to all studies, which may be due to differences between the study populations, diverse genetic backgrounds, or heterogeneous metabolic phenotypes between different BMI categories. Importantly, these studies provide evidence that obesity is associated with DNA methylation changes in blood leukocytes. One recent paper has addressed a question whether obesityassociated metabolic syndrome differs from obesity without metabolic complications by studying adipose tissue. Guenard et al. identified over 3,000 genes and 41 pathways differentially methylated between the two groups [22].

Genome-wide methylation studies are greatly enhanced by the usage of samples of trait-discordant monozygotic (MZ) twins. MZ twin pairs have the same genomic sequence, and the study design thus controls for the genetic diversity that has encumbered previous studies comparing obese and lean groups. In addition to being genetically identical (excluding rare somatic mutations [23-25] and structural variations [26-28]), MZ twins are matched for many confounding factors (for example, age, sex, family background). Thus, the co-twin control design is ideal when identifying epigenetic changes induced by lifestyle and acquired obesity.

The aim of this study was to identify DNA methylation marks associated with acquired obesity with or without metabolic dysregulation and thereby to identify potential epigenetic biomarkers for unhealthy obesity. To do this, we studied genome-wide DNA methylation patterns and associated chromatin states in 30 extremely rare, clinically healthy young adult $\mathrm{MZ}$ twin pairs discordant for BMI, identified from population-based twin cohort studies comprising ten birth cohorts ( $n=5,200$ pairs). Detailed phenotyping for adiposity and metabolic status enabled further stratification into two metabolically distinct subgroups characterized by either elevated or normal liver fat in the heavy co-twins. The heavy co-twins with elevated liver fat present several blood metabolic alterations, such as increased amounts of glucose, lipid, cytokines, and coagulation factors [2]. As all of these are overproduced by the fatty liver [29], liver fat accumulation is an interesting intermediate phenotype linking obesity-related comorbidities and the search for novel epigenetic markers in blood DNA. This distinction revealed DNA methylation differences in the obesity subtype with elevated liver fat and associated metabolic disturbances and thereby shows that blood epigenetic profiling has a great potential to better characterize the obesity phenotype, and identify subjects most at risk for developing metabolic complications.

\section{Results}

\section{Metabolic characterization of $\mathrm{MZ}$ twins}

We studied MZ twin pairs discordant for BMI (delta BMI $>3 \mathrm{~kg} / \mathrm{m}^{2}$, range 3 to $10.13 \mathrm{~kg} / \mathrm{m}^{2}, n=30$ ) and concordant for BMI (delta $\mathrm{BMI}<1.6 \mathrm{~kg} / \mathrm{m}^{2}$, range 0 to $\left.1.6 \mathrm{~kg} / \mathrm{m}^{2}, n=10\right)$. Among the BMI discordant pairs, the co-twins differed for subcutaneous, intra-abdominal and liver fat $(P<0.001$, Additional file 1$)$ and overall adiposity. No differences in these measures were observed in the BMI concordant pairs. In the discordant pairs, all measures of adiposity increased linearly for each unit increase of BMI, except for liver fat. In half of the discordant pairs for whom liver fat was measured $(n=12)$, both co-twins had low liver fat content (approximately 1\% triglycerides from liver weight) whereas in the other half $(n=13)$, the heavier co-twins had an increase (on average 509\%) in liver fat compared to the leaner co-twins $(P=0.0015$, Additional file 1). Both liver fat concordant and discordant groups were equally discordant for BMI (mean BMI difference $5.9 \mathrm{~kg} / \mathrm{m}^{2}$ for the liver fat concordant and $4.9 \mathrm{~kg} / \mathrm{m}^{2}$ for the liver fat discordant, the distributions of BMI and liver fat discordances are shown in Additional file 2: Figure S1), 
as well as for subcutaneous and intra-abdominal fat (within-pair difference $P<0.01$ for all, Additional file 1). In accordance with the known harmful metabolic effects of fatty liver, the pairs with large differences in liver fat were also highly discordant for several physiological parameters. In this group, the heavier co-twins had significantly higher fasting insulin and Homeostasis Model Assessment (HOMA) index, larger area under the curve (AUC) glucose and insulin during the oral glucose tolerance test (OGTT), higher low-density lipoprotein (LDL) and lower high-density lipoprotein (HDL) cholesterol, and higher high-sensitivity $\mathrm{C}$-reactive protein (CRP) than their leaner co-twins (Additional file 1). They also had higher diastolic blood pressure. None of these differences, except for HDL, were observed in the group where the heavier co-twins had normal levels of liver fat. Based on these within-pair differences in the metabolic profiles, we hereafter refer to the pairs discordant for BMI but concordant for liver fat as the normal liver fat (nLF) group and the pairs discordant for both BMI and liver fat as the elevated liver fat (eLF) group. The within-pair differences in glucose tolerance and liver fat were different between these two groups (AUC glucose, $P=0.04$; liver fat $\%, P=3.85 \times 10^{-07}$, Additional file 1 ). The heavy cotwins from the nLF and eLF groups differed for liver fat $\left(P=7.69 \times 10^{-07}\right)$ and fasting insulin $(P=0.02)$.

\section{Technical and biological variation}

Genome-wide DNA methylation was measured in whole blood using the Infinium HumanMethylation 450 BeadChip (Illumina). We applied stringent quality control and filtering procedures to minimize technical variation. To test for the reliability and consistency of the data, we conducted three experiments. First, to ensure that the 450 BeadChip identifies genuine DNA methylation differences between MZ co-twins rather than artificial differences due to technical variation, we hybridized two technical replicates of six different samples on the bead chips. DNA methylation patterns of the technical replicates were highly similar, showing greater resemblance among the replicates (Euclidean distance, ED $=12.24$ ) than withintwin pairs $(E D=13.86$ for concordant and 15.75 for discordant pairs), and greater similarity within pairs than between-same sex unrelated individuals $(E D=21.65$, Additional file 2: Figure S2). This indicates high quality of the data and that the within-pair methylation variation exceeds the technical variation. Second, to validate the within-pair DNA methylation differences, we performed EpiTYPER MassARRAY analysis on eight selected CpGs differentially methylated in the eLF group. Mean Pearson correlation of methylation differences at all CpGs between 450 BeadChip and EpiTYPER was 0.87, ranging from 0.65 to 0.96 (Additional file 2: Figure S3). This clearly shows that the observed differences in DNA methylation between MZ co-twins are genuine. Third, to validate the accuracy of the genome-wide DNA methylation mapping using the 450 BeadChip, we compared data generated by the Infinium platform and reduced representation bisulfite sequencing (RRBS) [30] from a different set of MZ twin pairs discordant for psoriasis (Gervin, $\mathrm{K}$ et al. manuscript in preparation). We observed a mean Pearson correlation of 0.96 across all CpGs covered by both methods (an Infinium probe and at least ten RRBS reads, $n=60,000$ ) in ten representative samples (Additional file 2: Figure S4). This is in agreement with a previous study [31] and demonstrates the robustness of the Infinium technology.

\section{Estimated proportions of CD4+ cells and granulocytes differ within pairs}

Our data are derived from peripheral whole blood, which comprises a mixture of different cell types. These cell types display different DNA methylation profiles, which can potentially confound the analyses if the proportions of the different cell types vary between cases and controls. Because the obese co-twins of the eLF group show low-grade inflammation as part of their metabolically disturbed obesity phenotype, and this is likely to affect the cell-type composition, we estimated the cell-type compositions in each sample. To do this, we applied a statistical algorithm predicting distributions of six blood cell types based on cell-specific 450 BeadChip methylation signatures [32]. These cell-type estimates revealed within-pair differences in granulocytes and CD4+ cells (false discovery rate (FDR) 0.02, Additional file 3) in the eLF group while the cell-type proportion estimates did not differ within the pairs in the nLF group. As the script for estimating the cell-type compositions is based on isolated cells from only 7 males [32], we investigated the accuracy of the estimated cell counts using 10 individuals from our twin cohort with both $450 \mathrm{~K}$ methylation data and differential blood cell counts. We found inconsistencies between the estimates and real cell counts as demonstrated by the moderate to low correlation coefficients $(r=0.64, P=0.05$ for lymphocytes; $r=0.74, P=0.02$ for granulocytes; and $r=0.24, P=$ 0.5 for monocytes). Due to these inconsistencies and, moreover, as our primary interest was to explore the DNA methylation fingerprint of 'unhealthy obesity', characterized by high liver fat and several preclinical metabolic alterations (Additional file 1), and to find potential novel biomarkers that help in the detection of this complex phenotype, we decided not to correct the data with cell-type estimates prior to differential methylation analysis. By correcting we would have over-adjusted our data and missed important associations between DNA methylation and liver fat (see Additional file 4, and Additional file 2: Figure S5, for unadjusted versus cell-type adjusted data). 


\section{Obesity-associated DNA methylation differences are associated with elevated liver fat}

MZ co-twins were in general highly correlated for DNA methylation across all CpGs (mean $=0.996$, range $=0.994$ to 0.997$)$. After correction for multiple testing and applying a biological relevance cutoff (mean within-pair methylation difference of $\geq 5 \%$ ), none of the $\mathrm{CpG}$ sites were differentially methylated within the $30 \mathrm{BMI}$ discordant twin pairs, nor in the 10 BMI concordant pairs (data not shown). Because the phenotypic characterization of these twins clearly identified two metabolically distinct groups, we sought to test the hypothesis that the eLF and nLF groups differ for their blood methylation profiles. While none of the CpGs were differentially methylated in the nLF group, 1,236 CpGs in 765 genes were differentially methylated in the eLF group (FDR $<0.05$, mean within-pair difference $\geq 5 \%, n$ $=13$, range of mean methylation difference 0.05 to 0.11 , Figure 1 and Additional file 4, and Additional file 2: Figure S6). In agreement with our hypothesis above, 1,042/1,236 CpGs showed different within-pair methylation discordances between the eLF and nLF groups
$(P<0.05$, Figure 2$)$. This clearly demonstrates that the epigenetic dissimilarity is consistent with differences in metabolic parameters between the two groups.

\section{DNA methylation differences in obesity-associated genes}

The genes located $<10 \mathrm{~Kb}$ away from the SNPs or CpGs identified by genome-wide association studies (GWAS) [33-50] and EWAS [7,17,18,51-56] for obesity, liver fat, T2DM, and metabolic syndrome (MetS), which are covered by the $450 \mathrm{~K}$ bead chip (23 out of 247 genes retrieved from previous publications and from GWAS catalog www.ebi.ac.uk/gwas), were overrepresented among the 765 genes identified in the eLF group (Fisher's exact test, $P=1.56 \times 10^{-4}$, Figure 1, Additional files 5 and 6).

\section{Differentially methylated CpGs are overrepresented at promoters, insulators, and repressed states and are enriched for hypomethylation}

The genomic distribution of the differentially methylated CpGs in relation to CpG density (CGIs, shores, shelves,

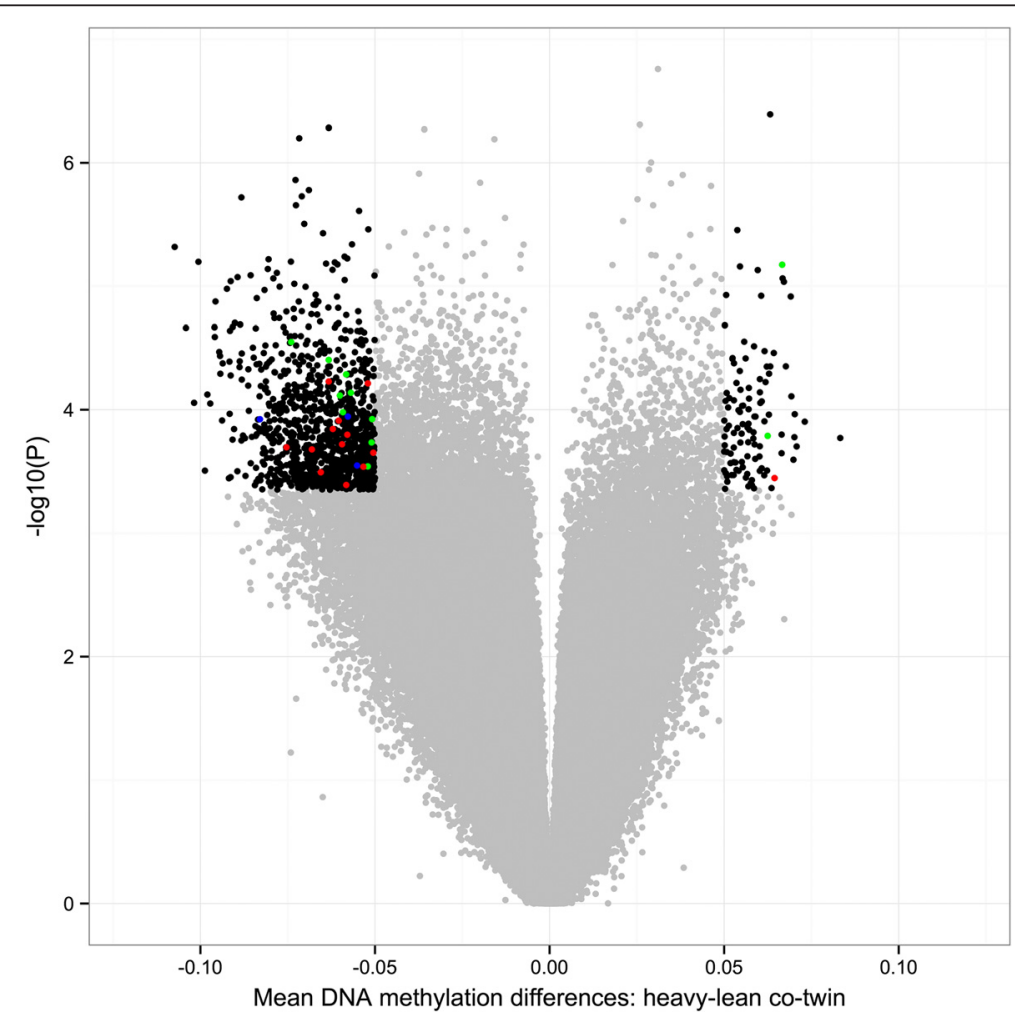

Figure 1 Volcano plot of differences in DNA methylation between the discordant co-twins $(n=13$ twin pairs) in the eLF group. Each point represents a CpG site $(n=456,961)$ with mean within-pair differences in DNA methylation between co-twins on the $x$-axis and - log 10 of the uncorrected $P$ value from a paired test (moderated empirical Bayes) on the $y$-axis. Negative methylation differences indicate hypomethylation and positive differences hypermethylation in the heavy compared to the lean co-twins. Black dots represent significantly differentially methylated CpGs $(n=1,236$, FDR $<0.05$, mean within-pair DNA methylation difference $\geq 5 \%$ ); red dots represent CpGs located in genes genetically associated with obesity and obesity-associated traits (T2DM, liver fat, and MetS, $n=13$, Additional file 5); green dots represent CpGs located in genes previously shown to be differentially methylated in obesity and T2DM ( $n=11$, Additional file 6); blue dots represent CpGs located in genes genetically and epigenetically associated to obesity and obesity-associated traits ( $n=3$, Additional files 5 and 6 ). 


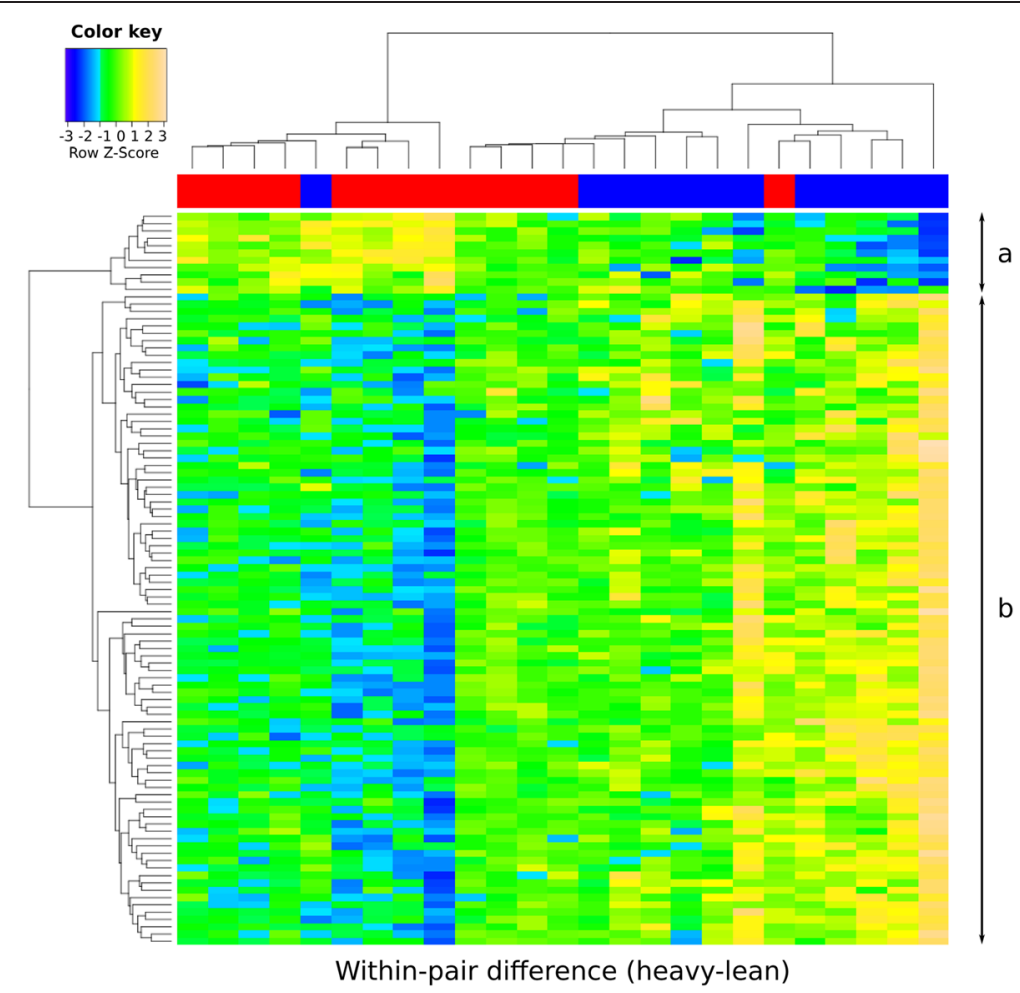

Figure 2 Heat map of within-pair DNA methylation differences show clustering of the eLF and nLF groups. Heat map of the within-pair DNA methylation differences (heavy-lean) at the top 100 most discordant CpGs (rows) identified in the eLF group show clustering of twin pairs (columns) in the eLF (red bar) and nLF (blue bar) groups. Color scale from blue to yellow represents the level and direction of within-pair methylation difference as Z-scores from negative towards positive values. (a) Heavy co-twins are more often hypermethylated relative to the lean co-twins in the eLF group and more often hypomethylated in the nLF group. (b) Heavy co-twins more often hypomethylated compared to the lean co-twins in the eLF group, and more often hypermethylated in the nLF group.

and open sea) in the eLF group was clearly different compared to the whole array CpG distribution (Figure 3). The differentially methylated $\mathrm{CpGs}$ were under-represented in CGIs and overrepresented in shelves and open seas. We also explored the location of the differentially methylated CpGs in relation to known and predicted functional elements in the genome (ChromHMM) by the use of ENCODE data from cell line GM12878 [57]. ChromHMM uses ChIP-seq data (CTCF and eight histone marks) to generate 15 chromatin states which are grouped to predict functional elements [58]. Based on the chromatin states, differentially methylated CpGs were overrepresented at active promoters, insulators, and within repressed and heterochromatic states and underrepresented at enhancers and transcribed sites (Figure 4).

Most of the differentially methylated CpGs were less methylated in the DNA from the heavy compared to the lean co-twins $\left(1,121 / 1,236,91 \%, P<2.2 \times 10^{-16}\right.$, Figure 1$)$ of the eLF group. In addition, based on the predicted chromatin states in the reference cell line, the functional genomic distribution of the hypo- and hypermethylated CpGs in the heavy co-twins showed distinct differences (Figure 5). Repressed chromatin and regions with weak

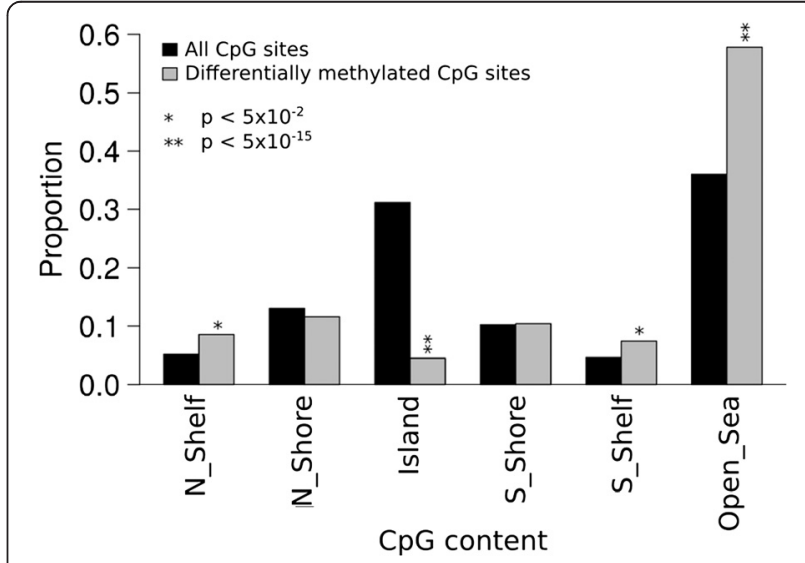

Figure 3 CGls underrepresented and open seas overrepresented among the differentially methylated CpGs. Bar plot shows the proportions of the differentially methylated CpGs at CGIs, shores, shelves, and open sea and the $P$ values denote which of the CpG categories are over- or underrepresented among the differentially methylated CpGs $(n=1,236)$ in the eLF group. Fisher's exact test was used to generate $P$ values for each group to see if they are under- or overrepresented among the 1,236 CpGs. Open sea, isolated CpGs outside any CGls; shelves, 2 to $4 \mathrm{~kb}$ from CGl; CGl shores, <2 kb from CGI. 


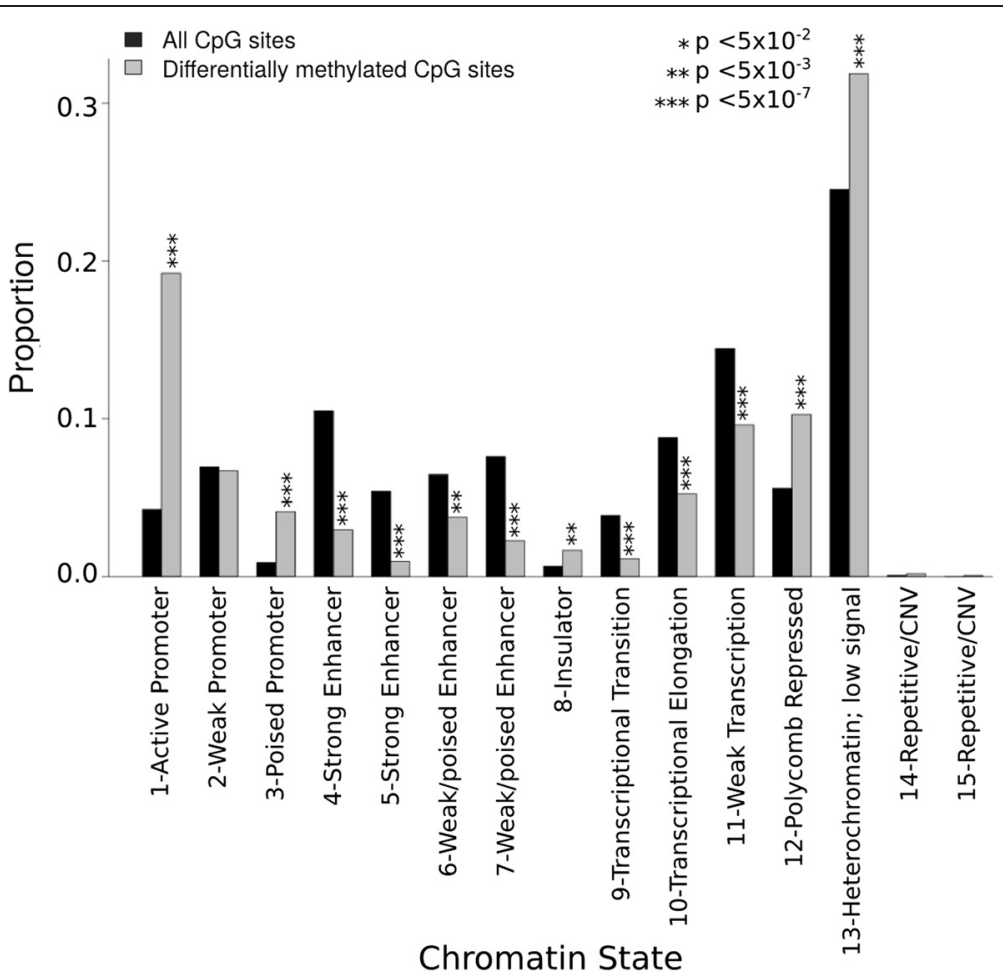

Figure 4 Chromatin states at the differentially methylated CpGs. Bar plot shows the proportions of 15 chromatin states using the Chromatin State Segmentation data from ENCODE/Broad Institute and which of the states are over- or underrepresented (Fisher's exact test) among the differentially methylated CpGs $(n=1,236)$ in the eLF group. Chromatin states with identical names differ from each other by the frequency of each mark [58].

transcription and transcription elongation were more often hypomethylated $(P<0.05)$ and active promoters and strong enhancers hypermethylated $(P<0.05)$ in the obese co-twins.

Enrichment of gene sets and pathways relevant for obesity Next, we performed gene set analysis (GSA) [59] to explore the potential of shared biologically relevant pathways among the obesity-associated methylation events. GSA of the BMI discordant group without stratification by liver fat discordance revealed only two enriched pathways (Table 1). Liver fat-stratified GSA did not reveal any pathways in the nLF group (data not shown); however, nine pathways showed enrichment in the eLF group (FDR $<0.1$, Table 1). Altogether eight of these pathways were less methylated in the heavy compared to their lean co-twins (Table 1). As shown in Additional file 2: Figure S7, vitamin- and amino acid-related pathways formed a linked network. To interpret the GSA data in the context of biological processes, pathways, and networks, the Core Analysis function in Ingenuity Pathways Analysis (IPA) (Ingenuity System Inc, USA) was performed for genes that map to the significant KEGG pathways from GSA (Additional file 7). Both GSA and IPA gave strong indications that the differentially methylated genes are involved with lipid, vitamin, and amino acid metabolism and immune and endocrine systems and liver dysfunction (Table 1).

Metabolic measures lend support to the pathway findings In light of the pathway results, we determined serum levels of linoleic acid, glycine, and histidine (Additional file 1). In the eLF group, the heavy co-twins had less linoleic acid than their lean co-twins. This was not seen in the nLF group where the relative circulating linoleic acid amount was similar in both co-twins. Also, glycine concentrations were reduced in the heavy co-twins of the eLF, but not of the nLF group. Histidine levels did not differ between the co-twins in either of the groups.

\section{Discussion}

To our knowledge, this is the first comprehensive genomewide leukocyte DNA methylation survey in MZ twin pairs discordant for BMI. Regardless of the within-pair discordance in BMI, the MZ twin pairs were highly similar for their methylation profiles, which is in line with previous DNA methylation studies using trait-discordant MZ twin pairs [60-67]. We show that DNA methylation profiles in blood leukocytes differ between BMI-discordant MZ cotwins only when high BMI is coupled with elevated liver 


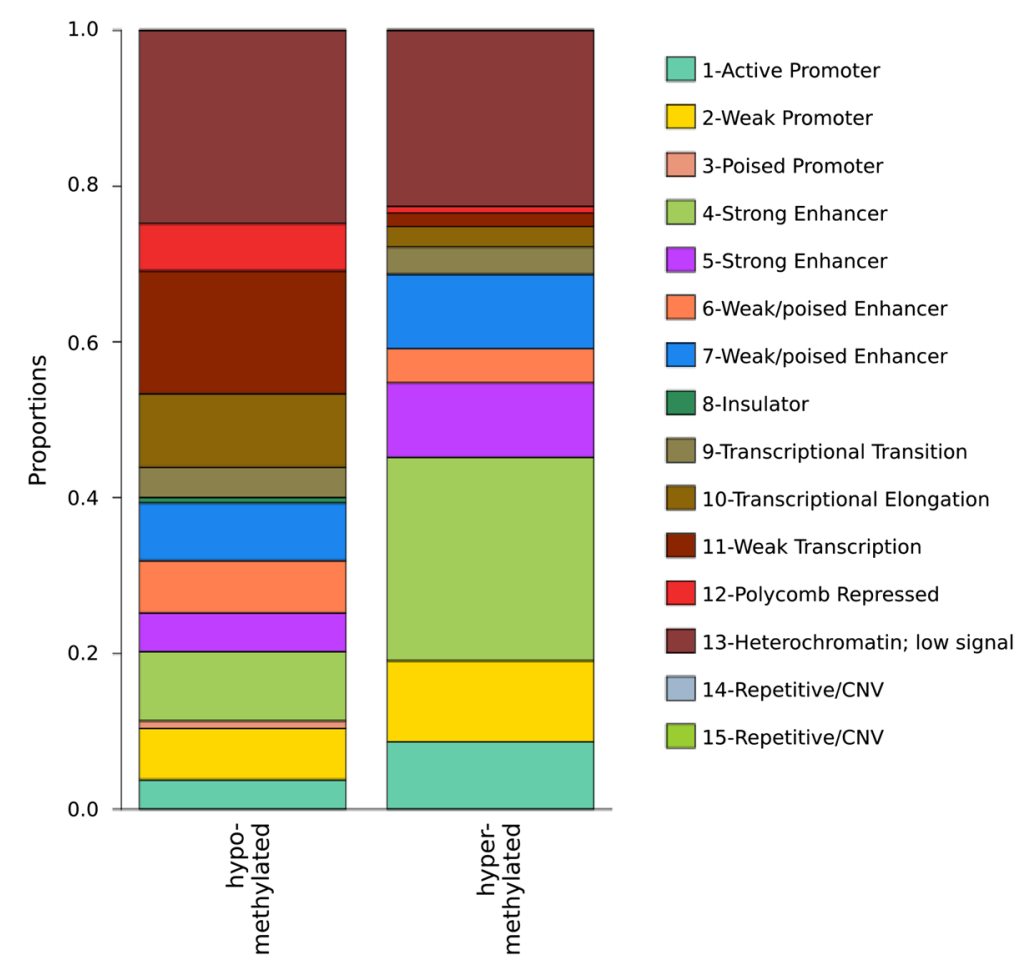

Figure 5 Proportions of hypo- and hypermethylated CpGs in the heavy co-twins in relation to chromatin states. The distributions of the hypo- and hypermethylated CpGs in relation to chromatin states differ greatly. Most of the hypomethylated CpGs were within heterochromatin (25\%) whereas hypermethylated CpGs were most common at strong enhancers (26\%).

fat and preclinical state metabolic disturbances (insulin resistance, low-grade inflammation, and dyslipidemia). This suggests that specific DNA methylation marks may identify obese individuals susceptible for the development of metabolic comorbidities. Altogether $91 \%$ of the differentially methylated CpGs were hypomethylated in the unhealthy obese as compared to their lean co-twins, including heterochromatic and repressed regions and promoters and insulators of both novel and known obesity-associated trait genes. The pathway analyses revealed clustering of the differentially methylated genes in vitamin (especially biotin and retinol), fatty acid, amino acid, and sulfur metabolism and to the renin-angiotensin system. These results suggest that the epigenetic signatures related to

Table 1 Enriched KEGG pathways

\begin{tabular}{|c|c|c|c|c|c|c|c|}
\hline \multicolumn{2}{|c|}{ KEGG pathway } & Score & $P$ value & FDR & CTEA score & CTEA $P$ value & CTEA FDR \\
\hline \multicolumn{8}{|c|}{ BMI discordant } \\
\hline 4977 & Vitamin digestion and absorption & -0.23 & 0.002 & 0.098 & -0.23 & 0.002 & 0.065 \\
\hline 4614 & Renin-angiotensin system & -0.23 & 0.003 & 0.098 & -0.22 & 0.009 & 0.195 \\
\hline \multicolumn{8}{|c|}{ eLF group } \\
\hline 260 & Glycine, serine and threonine metabolism & -0.19 & $<0.001$ & $<0.001$ & -0.16 & 0.001 & 0.033 \\
\hline 340 & Histidine metabolism & -0.13 & 0.002 & 0.052 & -0.12 & 0.005 & 0.065 \\
\hline 4977 & Vitamin digestion and absorption & -0.19 & 0.003 & 0.052 & -0.15 & 0.020 & 0.130 \\
\hline 4614 & Renin-angiotensin system & -0.22 & 0.004 & 0.052 & -0.24 & 0.001 & 0.033 \\
\hline 300 & Lysine biosynthesis & -0.48 & 0.004 & 0.052 & -0.44 & 0.003 & 0.065 \\
\hline 780 & Biotin metabolism & -0.61 & 0.006 & 0.056 & -0.64 & 0.009 & 0.084 \\
\hline 920 & Sulfur metabolism & -0.29 & 0.006 & 0.056 & -0.29 & 0.006 & 0.065 \\
\hline 591 & Linoleic acid metabolism & 0.36 & 0.001 & 0.065 & 0.49 & $<0.001$ & $<0.001$ \\
\hline 830 & Retinol metabolism & -0.11 & 0.011 & 0.089 & -0.19 & 0.005 & 0.065 \\
\hline
\end{tabular}

1,000 permutations were performed with no probe number cutoffs. CTEA cell-type estimate adjusted. 
unhealthy obesity may involve nutritional factors, as well as point to possible new pathogenic routes to obesityrelated diseases with implications for treatment.

Liver is a key metabolic regulator, and when fatty, it overproduces glucose, lipids, and inflammatory cytokines [68]. In turn, low liver fat has been suggested to be a hallmark of the so-called healthy obesity [69]. Here, as well as in our previous study [2], we showed that high liver fat is associated with several preclinical metabolic aberrations in obesity, including increased glucose, insulin, lipid, and CRP levels. With this in mind, it seems clear that the blood environment for the circulating leukocytes is different in subjects with high liver fat compared to those with low liver fat, that is, in those with or without metabolic aberrations. Because measurement of liver fat is laborious, blood epigenetic profiles together with metabolic surrogate markers may provide an attractive additional tool for the diagnosis and search for therapeutic targets in the future [29].

Among the differentially methylated genes in the eLF group, 23 have been previously found to be associated with obesity and obesity-associated traits in multiple GWAS meta-analyses and DNA methylation studies. For example, hypermethylation of $U B A S H 3 A$ and hypomethylation of THADA were found in the present as well as in previous studies [17,51].

We found that most of the differentially methylated CpGs were hypomethylated and associated with chromatin states marking important regulatory elements [52] and that differentially methylated CpGs were overrepresented at CGI shelves and open seas, and underrepresented at CGIs. This is in accordance with previous studies investigating disease-associated methylation patterns [70-73]. We also explored chromatin states at differentially methylated CpGs using ENCODE data and showed overrepresentation of promoters and insulators, suggesting that the methylation differences may have functional consequences by fine-tuning transcription of the associated genes. Unfortunately, no RNA is available from the study material to explore this hypothesis further.

We identified a large number of differentially methylated CpGs between co-twins highly discordant for liver fat and BMI. This was not a surprise as multiple genes in many pathways are likely to be differentially regulated in unhealthy obesity, and because we reported the 'total' within-pair methylation differences including both direct and indirect (via cell-type variation) obesity-associated methylation marks.

It is known that different cell subpopulations in peripheral blood may display different DNA methylation profiles. Consequently, there is a lot of discussion regarding the impact of cell-type heterogeneity on epigenetic studies performed on whole blood [74-81]. We acknowledge that our DNA methylation findings in the eLF group may be partly due to differences in cell-type proportions within pairs. Indeed, this may be the case in most studies comparing normal tissue to diseased tissue. Hence, in studies aiming to identify biomarkers for a disease state, adjusting for cell-type distributions could be overadjustment leading to false negative findings. Even though co-twins from the eLF group differ for their estimates of granulocytes and CD4+ cells, the most prominent clinical parameters, liver fat, insulin resistance, and low grade inflammation, were only weakly correlated with the celltype estimates. Regardless of the source of the observed methylation differences, our cell-type unadjusted methylation data distinguishing high BMI with and without a fatty liver may have a value for future development of diagnostic biomarker panels for early metabolic disturbances in obesity because such practical tools will be based on DNA from whole blood samples, not specific cell types. Further, the methylation profile of the eLF group may also serve as a useful tool in imputing the liver fat phenotype in epidemiological studies.

Like in any human study, we cannot exclude differences in all potential environmental factors within the twin pairs that may have an effect on DNA methylation. For example, recent alcohol intake has been shown to have genome-wide effects on blood DNA methylation [82]. Given the cross-sectional nature of our study, the direction of causality cannot be proven. We believe that only a minority of the observed methylation differences preceded obesity, but are mainly due to a complex mixture of different metabolic and clinical parameters (including blood cell-type heterogeneity), which are related to the complex phenotype differences between the lean and metabolically disturbed heavy co-twins characterized by elevated liver fat levels. However, we cannot preclude the possibility that some of the findings are indicative of processes that precede the onset of weight gain. Nevertheless, our main conclusion is that the observed epigenetic signature truly reflects the phenotype and characterizes the heavy twins in the eLF group.

\section{Conclusions}

The present study shows that epigenetic profiling has a great potential to better characterize the obesity phenotype and identify subjects most at risk for developing metabolic complications. The metabolically disadvantaged obese MZ twins, with high liver fat, insulin resistance, inflammation, and dyslipidemia, were characterized by differential blood DNA CpG methylation in a number of novel and known obesity-associated genes when compared to the methylation levels of their lean counterparts. The pathways linked to the unhealthy obesity were related to vitamin, amino and fatty acid, renin-angiotensin, and sulfur metabolism. These results may harbor clues to the etiology, such as nutritional defects in the development of 
metabolic derangements. In addition to their potential role in diagnostics of the metabolic disturbances, the findings may help expedite the search for novel therapeutic targets for obesity.

\section{Methods \\ Twin collection}

The twin pairs were selected from two population-based longitudinal studies, FinnTwin16 and FinnTwin12, each consisting of five consecutive birth cohorts of Finnish twins [83]. Altogether $30 \mathrm{BMI}$ discordant (within-pair difference (delta) in BMI $\geq 3 \mathrm{~kg} / \mathrm{m}^{2}$ ) and 10 BMI concordant (delta BMI $<1.6 \mathrm{~kg} / \mathrm{m}^{2}$ ) MZ twin pairs were selected from the last follow-ups $[2,84]$. The range of the BMI of the lean co-twins was 19.7 to $40.6 \mathrm{~kg} / \mathrm{m}^{2}$ and of the heavy co-twins was 24.2 to $48.6 \mathrm{~kg} / \mathrm{m}^{2}$. Twins with concomitant somatic and psychiatric diseases or medications (except for oral contraceptives) were excluded.

The twin pairs ( $n=40,17$ males, 23 premenopausal females) were $27 \pm 3.3$ (mean \pm SD) years old. Their weight had been stable for at least 3 months prior to the study. Zygosity was confirmed by genotyping of ten informative genetic markers [85]. The subjects provided written informed consent. The protocol was designed and performed according to the principles of the Helsinki Declaration and was approved by the Ethics Committee of the Helsinki University Central Hospital.

\section{Phenotypic measurements}

Weight and height were measured, after overnight fast, barefoot and in light clothing, to calculate BMI. Body composition was measured using whole body dual-energy $\mathrm{x}$-ray absorptiometry (DEXA) [86]. Abdominal fat distribution and liver fat content were measured with a clinical magnetic resonance (MR) imager (1.5 Tesla, Avanto, Siemens, Erlangen, Germany) for MR imaging and MR spectroscopy [87]. MR images were analyzed using SliceOmatic v4.3 segmentation software and the results were expressed as total volumes of SAT and VAT. The liver spectra were analyzed with jMRUI v3.0 software [88] using the AMARES algorithm [89].

After 12-h overnight fast, subjects underwent a $75-\mathrm{g}$ OGTT. Concentrations of plasma glucose were measured using the spectrophotometric hexokinase and glucose-6phosphate dehydrogenase assay (Gluko-quant glucose/ hexokinase, Roche Diagnostics, Tokyo, Japan) with a Hitachi Modular automatic analyzer (Hitachi, Tokyo, Japan), and serum insulin with time-resolved immunofluorometric assay (Perkin Elmer). Areas under the plasma glucose response curve (AUC glucose) and the serum insulin response curve (AUC insulin) were calculated from fasting, 30-, 60-, and 120-min glucose and insulin concentrations, with the trapezoid rule. The insulin resistance index (HOMA-IR) was calculated during OGTT according to Matthews et al.
[90]. Total HDL cholesterol and triglyceride concentrations in serum were measured freshly by enzymatic methods (Roche Diagnostics Hitachi, Tokyo, Japan). LDL cholesterol concentrations were calculated using the Friedewald formula. Serum hsCRP was measured by particle-enhanced immunoturbidimetric assay (Cobas CRP(Latex)HS, Roche Diagnostics) on Modular automatic analyzer (Hitachi Ltd, Tokyo, Japan). Serum fatty acid and amino acid profiles were measured by proton NMR spectroscopy [91].

\section{DNA extraction and bisulfite conversion}

High molecular weight DNA was extracted from whole blood using QIAamp DNA Mini kit (QIAGEN Nordic, Sollentuna, Sweden). Bisulfite conversion of DNA was completed using EZ-96 DNA Methylation-Gold Kit (Zymo Research, Irvine, CA, USA) according to the manufacturer's instructions, and the co-twins were always converted on the same plate to minimize potential batch effects.

\section{DNA methylation analysis}

DNA methylation status was assessed using the Infinium HumanMethylation 450 BeadChip, performed by the Microarray Consortium (Oslo, Norway) according to manufacturer's instructions (Illumina, San Diego, CA, USA). The co-twins were always hybridized on the same chip.

All analyses were carried out using the $\mathrm{R}$ programming language (http://www.r-project.org/, v2.15) and Bioconductor (v2.10) [92]. The raw data was preprocessed using methylumi [93] and normalized using quantile normalization followed by beta-mixture quantile normalization (BMIQ). BMIQ effectively adjusts the data for the two different probe designs (Infinium type I and type II) on the array [94]. The ComBat function in the R package sva [95] was then used to correct for batch effects in the data. The data was filtered to remove probes with detection $P$ values above 0.001 in any sample (5,372 probes), probes covering non-CpGs $(3,063)$, and those mapping to $\mathrm{X}$ and $\mathrm{Y}$ chromosomes (11022). Further, Burrows-Wheeler Aligner (BWA) - short [96] - was used to identify probes that map to multiple locations in the genome (9,159 probes with $>1$ location), and all such probes were removed. This resulted in a final data set with 456,961 probes. Log2 ratios of methylated probe intensities to unmethylated probe intensities, the M-values, were then generated using functions in the $\mathrm{R}$ package lumi. Illumina Manifest was used for probe annotations.

Validation of within-pair differences at eight differentially methylated CpGs (in seven genes) in the eLF group was done by EpiTYPER MassARRAY (SEQUENOM Inc., Hamburg, Germany). PCR primers (Additional file 8) were designed using SEQUENOM's EpiDesigner BETA (SEQUENOM Inc., Hamburg, Germany) tool (www.epidesigner.com). To reduce methylation variability introduced during PCR [97], triplicate 
amplifications of each sample were performed and pooled prior to MassARRAY analysis. PCR amplification was performed as in [98] and methylation status of each CpG was determined according to the manufacturer's instructions.

\section{Statistical analysis}

All differential methylation analyses were performed using $\mathrm{M}$-values, and beta-values, ranging from 0 to 1 ( 0 to $100 \%$ methylation), were used to report the outcomes of the analyses. Statistical tests were conducted in R and Stata statistical software (release 12.0; Stata Corporation, College Station, TX). Comparisons of the clinical parameters within twin pairs were made by Wilcoxon signedrank tests. Correlation of DNA methylation within discordant MZ twin pairs was computed as Pearson correlation and similarity as Euclidean distances (ED).

The level of discordance in technical replicates, twin pairs, and unrelated pairs was compared by using the mean of the ED in methylation within technical replicates of six samples, three randomly selected BMI concordant twin pairs and six randomly selected unrelated, same-sex individuals. Empirical cumulative distribution function (ECDF) plots were generated using means of the withinpair differences in the three pairs in each group. Probes containing SNPs $(n=59,892)$ were not included in computing the EDs or generating the ECDF plots. Furthermore, an algorithm developed by Houseman et al. [32] was utilized to determine the proportions of the white blood cell types $\left(\mathrm{CD} 4^{+}\right.$and $\mathrm{CD}^{+}{ }^{+} \mathrm{T}$ cells, $\mathrm{CD} 56^{+}$ NK cells, B cells, monocytes, and granulocytes).

Differential methylation analysis was performed after adjusting the data for smoking, using empirical Bayes paired moderated $t$ statistics implemented in the R package limma [99]. The raw $P$ values from the paired tests were corrected for multiple testing using the Benjamini and Hochberg (BH) method. CpG sites with FDR $<0.05$ and within-pair methylation difference of $\geq 5 \%$ were called as differentially methylated. Moderated $t$ statistics with $\mathrm{BH}$ correction was also used to compare the within-pair difference of twin pairs between groups to examine whether the identified within-pair methylation discordances were group specific.

The genomic distribution of the 1,236 differentially methylated CpGs, in relation to CGIs, was compared with the distribution of the CpGs in the whole data set. $P$ values were computed using the Fisher's exact test to determine over- or under-representation of the CpGs in relation to CGIs.

ENCODE data (ChromHMM on cell line GM12878, Broad Institute, Cambridge, MA, USA) was used to determine the chromatin state at each of the 1,236 CpGs by finding overlaps in the regions defined in the ENCODE data and the probe locations. $P$ values were computed using Fisher's exact test to determine if the differentially methylated CpGs over- or under-represented any of the chromatin states.

\section{Gene set and pathway analyses}

The $R$ package GSA was used to find the significance of predefined sets of CpGs, each set representing a pathway on KEGG. GSA was applied on the within-pair differences in methylation and run with 1,000 permutations. A $P$ value cutoff of 0.05 and FDR cutoff of 0.1 were applied to obtain the list of significant pathways. GSA does not take into account the number of $\mathrm{CpG}$ sites on individual genes in a pathway; however, there was no obvious bias related to number of probes per genes (Additional file 2: Figure S8). The results give a list of pathways that need to be studied more closely. The genes in the significant KEGG pathways were further analyzed by IPA (Ingenuity Systems, Redwood City, CA, USA) to examine networks, functions, and associated diseases.

\section{Additional files}

Additional file 1: Anthropometric and metabolic measures of the $\mathrm{MZ}$ twin pairs in the study. Table with the characteristics of the study material. Additional file 2: A document with all supplementary figures ( $\mathrm{S} 1$ to S8) and figure legends. Figure S1: The distributions of BMI and liver fat discordances within pairs. Figure S2: Similarity of methylation between unrelated individuals, co-twins, and technical replicates. Figure S3: Validation of the within-pair DNA methylation differences. Figure S4: Comparisons of DNA methylation levels measured by Infinium 450 BeadChip and RRBS. Figure S5: QQ plots of observed $P$ values from the within-pair methylation analysis of the eLF group twin pairs before and after correcting the data with estimated cell count proportions. Figure S6: Distribution of mean within-pair methylation differences and observed $P$ values. Figure S7: Early onset liver fat-associated pathways form networks. Figure S8: Scatterplot of GSA results showing the mean number of probes per gene per pathway.

Additional file 3: Within-pair differences of the estimated cell type proportions. Table showing the within twin pair differences in the cell type estimates.

Additional file 4: Differentially methylated CpGs in the eLF group. Table listing the differentially methylated $\mathrm{CpG}$ sites with mean betas, mean delta betas, LogFC, and $P$ values before and after cell type estimate adjustments.

Additional file 5: Obesity and obesity-associated trait candidate genes identified by GWAS that are differentially methylated in the eLF group. Table listing differentially methylated CpG sites that are located in obesity and obesity-associated trait candidate genes identified by GWAS.

Additional file 6: Obesity and T2DM candidate genes identified by candidate gene DNA methylation or EWAS that are differentially methylated in the eLF group. Table listing differentially methylated CPG sites replicating previously published obesity and T2DM associated methylation.

Additional file 7: The top IPA networks among the significant pathways of the eLF group. Table showing the enriched networks produced by IPA.

Additional file 8: PCR primers for EpiTYPER MassARRAY analysis. Table showing the primer sequences used in the validation assays.

\section{Abbreviations}

BMI: body mass index; BMIQ: beta-mixture quantile normalization; CGIs: CpG islands; CpGs: CpG sites; ED: Euclidean distance; eLF group: elevated liver fat 
group; EWAS: epigenome-wide association studies; FDR: false discovery rate; GSA: gene set analysis; GWAS: genome-wide association studies; MetS: metabolic syndrome; MZ: monozygotic; nLF group: normal liver fat group; T2DM: type 2 diabetes mellitus.

\section{Competing interests}

The authors declare that they have no competing interests.

\section{Authors' contributions}

$M O, A R, K H P$, and JK conceived and designed the study. JK was responsible for the twin cohort data collection from which the study pairs were recruited. KHP collected the biological samples and performed the clinical investigations of the twins. MO coordinated the study and wrote the manuscript. KHP, JK, AR, $J R H, R L$, and EJ helped in drafting and critically commented on the manuscript. $\mathrm{KI}$ and $\mathrm{KG}$ performed the bioinformatics and $\mathrm{KI}, \mathrm{KG}, \mathrm{KHP}$, and $\mathrm{MO}$ the basic statistical analysis of the data. AK performed the validation experiments. RL participated in the design of the study and data analysis. NL, JL, and AH performed and analyzed the MR images. All authors participated in discussions related to analysis and interpretation and have read and approved the final manuscript.

\section{Acknowledgements}

We thank the participants for their invaluable contributions to the study. The Obesity Research Unit team and the staff at the Finnish Twin Cohort Study are acknowledged for their help in the collection of the data. Adjunct Professor Janne Pitkäniemi is thanked for his continuing support and advice in statistics. This study was supported by the Academy of Finland (grants 251316, 100499, 205585, 118555, 141054, 266286, and 272376), the Sigrid Juselius Foundation, Helsinki University Hospital Research Funds, grants from Novo Nordisk, Finnish Diabetes Research Foundation, Finnish Foundation for Cardiovascular Research, Biomedicum Helsinki, Jalmari and Rauha Ahokas Foundation, the Academy of Finland Center of Excellence in Complex Disease Genetics (grants 213506 and 129680), European Network for Genetic and Genomic Epidemiology (ENGAGE, FP7-HEALTH-F4-2007, grant agreement number 201413), a Molecular Targets Open for Regulation by the gut flora New Avenues for improved Diet to Optimize European health (TORNADO, FP7-KBBE-222720), EPITRAIN - Innovative techniques and models to understand epigenetic regulation in the pathogenesis of common diseases (EPITRAIN FP7-PEOPLE-2012-ITN, grant agreement 316758), and BioSHaRE-EU (grant agreement HEALTH-F4-2010-261433) funded by the European Union's Seventh Framework Programme (FP7/2007-2013).

\section{Author details}

${ }^{1}$ Department of Public Health, University of Helsinki, Helsinki, Finland. ${ }^{2}$ Department of Medical Genetics, Oslo University Hospital and University of Oslo, Oslo, Norway. ${ }^{3}$ Obesity Research Unit, Research Programs Unit, Diabetes and Obesity, University of Helsinki, Helsinki, Finland. ${ }^{4}$ Department of Radiology, HUS Medical Imaging Center, Helsinki University Central Hospital, University of Helsinki, Helsinki, Finland. ${ }^{5}$ Division of Epidemiology, The Norwegian Institute of Public Health, Oslo, Norway. ${ }^{6}$ Department of Psychiatry, Helsinki University Central Hospital, Helsinki, Finland. ${ }^{7}$ Endocrinology, Abdominal Center, Helsinki University Central Hospital, Helsinki, Finland. ${ }^{8}$ Institute for Molecular Medicine FIMM, University of Helsinki, Helsinki, Finland. ${ }^{9}$ Department of Mental Health and Substance Abuse Services, National Institute for Health and Welfare, Helsinki, Finland.

\section{Received: 17 October 2014 Accepted: 11 March 2015} Published online: 02 April 2015

\section{References}

1. Bluher M. Are there still healthy obese patients? Curr Opin Endocrinol Diabetes Obes. 2012;19(5):341-6.

2. Naukkarinen J, Heinonen S, Hakkarainen A, Lundbom J, Vuolteenaho K, Saarinen $L$, et al. Characterising metabolically healthy obesity in weightdiscordant monozygotic twins. Diabetologia. 2014;57(1):167-76.

3. Yki-Jarvinen $\mathrm{H}$. Non-alcoholic fatty liver disease as a cause and a consequence of metabolic syndrome. Lancet Diabetes Endocrinol. 2014;2(11):901-10.

4. Drummond EM, Gibney ER. Epigenetic regulation in obesity. Curr Opin Clin Nutr Metab Care. 2013;16(4):392-7.
5. Tobi EW, Lumey LH, Talens RP, Kremer D, Putter H, Stein AD, et al. DNA methylation differences after exposure to prenatal famine are common and timing- and sex-specific. Hum Mol Genet. 2009;18(21):4046-53.

6. Steegers-Theunissen RP, Obermann-Borst SA, Kremer D, Lindemans J, Siebel C, Steegers EA, et al. Periconceptional maternal folic acid use of 400 microg per day is related to increased methylation of the IGF2 gene in the very young child. PLoS One. 2009;4(11):e7845.

7. Godfrey KM, Sheppard A, Gluckman PD, Lillycrop KA, Burdge GC, McLean C, et al. Epigenetic gene promoter methylation at birth is associated with child's later adiposity. Diabetes. 2011;60(5):1528-34.

8. Dogan MV, Shields B, Cutrona C, Gao L, Gibbons FX, Simons R, et al. The effect of smoking on DNA methylation of peripheral blood mononuclear cells from African American women. BMC Genomics. 2014;15:151.

9. Shenker NS, Polidoro S, van Veldhoven K, Sacerdote C, Ricceri F, Birrell MA, et al. Epigenome-wide association study in the European Prospective Investigation into Cancer and Nutrition (EPIC-Turin) identifies novel genetic loci associated with smoking. Hum Mol Genet. 2013;22(5):843-51.

10. Zeilinger S, Kuhnel B, Klopp N, Baurecht H, Kleinschmidt A, Gieger C, et al. Tobacco smoking leads to extensive genome-wide changes in DNA methylation. PLoS One. 2013;8(5):e63812.

11. Houde AA, Guay SP, Desgagne V, Hivert MF, Baillargeon JP, St-Pierre J, et al. Adaptations of placental and cord blood ABCA1 DNA methylation profile to maternal metabolic status. Epigenetics. 2013;8(12):1289-302.

12. Houde AA, Hivert MF, Bouchard L. Fetal epigenetic programming of adipokines. Adipocyte. 2013;2(1):41-6.

13. El Hajj N, Pliushch G, Schneider E, Dittrich M, Muller T, Korenkov M, et al. Metabolic programming of MEST DNA methylation by intrauterine exposure to gestational diabetes mellitus. Diabetes. 2013;62(4):1320-8.

14. Kuehnen P, Mischke M, Wiegand S, Sers C, Horsthemke B, Lau S, et al. An Alu element-associated hypermethylation variant of the POMC gene is associated with childhood obesity. PLoS Genet. 2012;8(3):e1002543.

15. Stepanow S, Reichwald K, Huse K, Gausmann U, Nebel A, Rosenstiel P, et al. Allele-specific, age-dependent and BMI-associated DNA methylation of human MCHR1. PLoS One. 2011;6(5):e17711.

16. Guay SP, Brisson D, Lamarche B, Biron S, Lescelleur O, Biertho L, et al. ADRB3 gene promoter DNA methylation in blood and visceral adipose tissue is associated with metabolic disturbances in men. Epigenomics. 2014;6(1):33-43.

17. Wang X, Zhu H, Snieder H, Su S, Munn D, Harshfield G, et al. Obesity related methylation changes in DNA of peripheral blood leukocytes. BMC Med. 2010;8:87.

18. Almen MS, Jacobsson JA, Moschonis G, Benedict C, Chrousos GP, Fredriksson R, et al. Genome wide analysis reveals association of a FTO gene variant with epigenetic changes. Genomics. 2012;99(3):132-7.

19. Dick KJ, Nelson CP, Tsaprouni L, Sandling JK, Aissi D, Wahl S, et al. DNA methylation and body-mass index: a genome-wide analysis. Lancet. 2014;383(9933):1990-8.

20. Almen MS, Nilsson EK, Jacobsson JA, Kalnina I, Klovins J, Fredriksson R, et al. Genome-wide analysis reveals DNA methylation markers that vary with both age and obesity. Gene. 2014;548(1):61-7.

21. Horvath S, Erhart W, Brosch M, Ammerpohl O, von Schonfels W, Ahrens M, et al. Obesity accelerates epigenetic aging of human liver. Proc Natl Acad Sci U S A. 2014;111(43):15538-43.

22. Guenard F, Tchernof A, Deshaies Y, Perusse L, Biron S, Lescelleur O, et al. Differential methylation in visceral adipose tissue of obese men discordant for metabolic disturbances. Physiol Genomics. 2014;46(6):216-22.

23. Ye K, Beekman M, Lameijer EW, Zhang Y, Moed MH, van den Akker EB, et al. Aging as accelerated accumulation of somatic variants: whole-genome sequencing of centenarian and middle-aged monozygotic twin pairs. Twin Res Hum Genet. 2013;16(6):1026-32.

24. Weber-Lehmann J, Schilling E, Gradl G, Richter DC, Wiehler J, Rolf B. Finding the needle in the haystack: differentiating "identical" twins in paternity testing and forensics by ultra-deep next generation sequencing. Forensic Sci Int Genet. 2014;9:42-6.

25. Vogt J, Kohlhase J, Morlot S, Kluwe L, Mautner VF, Cooper DN, et al. Monozygotic twins discordant for neurofibromatosis type 1 due to a postzygotic NF1 gene mutation. Hum Mutat. 2011;32(6):E2134-47.

26. Forsberg LA, Rasi C, Razzaghian HR, Pakalapati G, Waite L, Thilbeault KS, et al. Age-related somatic structural changes in the nuclear genome of human blood cells. Am J Hum Genet. 2012;90(2):217-28.

27. Ehli EA, Abdellaoui A, Hu Y, Hottenga JJ, Kattenberg M, van Beijsterveldt T, et al. De novo and inherited CNVs in MZ twin pairs selected for 
discordance and concordance on attention problems. Eur J Hum Genet. 2012;20(10):1037-43

28. Breckpot J, Thienpont B, Gewillig M, Allegaert K, Vermeesch JR, Devriendt K. Differences in copy number variation between discordant monozygotic twins as a model for exploring chromosomal mosaicism in congenital heart defects. Mol Syndromol. 2012;2(2):81-7.

29. Oresic M, Hyotylainen T, Kotronen A, Gopalacharyulu P, Nygren H, Arola J, et al. Prediction of non-alcoholic fatty-liver disease and liver fat content by serum molecular lipids. Diabetologia. 2013;56(10):2266-74.

30. Boyle P, Clement K, Gu H, Smith ZD, Ziller M, Fostel JL, et al. Gel-free multiplexed reduced representation bisulfite sequencing for large-scale DNA methylation profiling. Genome Biol. 2012;13(10):R92.

31. Bock C, Tomazou EM, Brinkman AB, Muller F, Simmer F, Gu H, et al. Quantitative comparison of genome-wide DNA methylation mapping technologies. Nat Biotechnol. 2010;28(10):1106-14.

32. Houseman EA, Accomando WP, Koestler DC, Christensen BC, Marsit CJ, Nelson $\mathrm{HH}$, et al. DNA methylation arrays as surrogate measures of cell mixture distribution. BMC Bioinformatics. 2012;13:86.

33. Saxena R, Elbers CC, Guo Y, Peter I, Gaunt TR, Mega JL, et al. Large-scale gene-centric meta-analysis across 39 studies identifies type 2 diabetes loci. Am J Hum Genet. 2012;90(3):410-25.

34. Dastani Z, Hivert MF, Timpson N, Perry JR, Yuan X, Scott RA, et al. Novel loci for adiponectin levels and their influence on type 2 diabetes and metabolic traits: a multi-ethnic meta-analysis of 45,891 individuals. PLoS Genet. 2012;8(3):e1002607.

35. Speliotes EK, Willer CJ, Berndt SI, Monda KL, Thorleifsson G, Jackson AU, et al. Association analyses of 249,796 individuals reveal 18 new loci associated with body mass index. Nat Genet. 2010;42(11):937-48.

36. Thorleifsson G, Walters GB, Gudbjartsson DF, Steinthorsdottir V, Sulem $P$, Helgadottir A, et al. Genome-wide association yields new sequence variants at seven loci that associate with measures of obesity. Nat Genet. 2009;41(1):18-24.

37. Zeggini E, Scott LJ, Saxena R, Voight BF, Marchini UL, Hu T, et al. Meta-analysis of genome-wide association data and large-scale replication identifies additional susceptibility loci for type 2 diabetes. Nat Genet. 2008;40(5):638-45.

38. Chambers JC, Zhang W, Sehmi J, Li X, Wass MN, Van der Harst P, et al. Genome-wide association study identifies loci influencing concentrations of liver enzymes in plasma. Nat Genet. 2011:43(11):1131-8.

39. Kristiansson K, Perola M, Tikkanen E, Kettunen J, Surakka I, Havulinna AS, et al. Genome-wide screen for metabolic syndrome susceptibility loci reveals strong lipid gene contribution but no evidence for common genetic basis for clustering of metabolic syndrome traits. Circ Cardiovasc Genet. 2012;5(2):242-9.

40. Jiao H, Arner P, Hoffstedt J, Brodin D, Dubern B, Czernichow S, et al. Genome wide association study identifies KCNMA1 contributing to human obesity. BMC Med Genomics. 2011:4:51.

41. Wheeler E, Huang N, Bochukova EG, Keogh JM, Lindsay S, Garg S, et al Genome-wide SNP and CNV analysis identifies common and low-frequency variants associated with severe early-onset obesity. Nat Genet. 2013;45(5):513-7.

42. Berndt SI, Gustafsson S, Magi R, Ganna A, Wheeler E, Feitosa MF, et al. Genome-wide meta-analysis identifies 11 new loci for anthropometric traits and provides insights into genetic architecture. Nat Genet. 2013;45(5):501-12.

43. Comuzzie AG, Cole SA, Laston SL, Voruganti VS, Haack K, Gibbs RA, et al. Novel genetic loci identified for the pathophysiology of childhood obesity in the Hispanic population. PLoS One. 2012;7(12):e51954.

44. Frayling TM, Timpson NJ, Weedon MN, Zeggini E, Freathy RM, Lindgren CM, et al. A common variant in the FTO gene is associated with body mass index and predisposes to childhood and adult obesity. Science. 2007;316(5826):889-94.

45. Willer CJ, Speliotes EK, Loos RJ, Li S, Lindgren CM, Heid IM, et al. Six new loci associated with body mass index highlight a neuronal influence on body weight regulation. Nat Genet. 2009;41(1):25-34

46. Scuteri A, Sanna S, Chen WM, Uda M, Albai G, Strait J, et al. Genome-wide association scan shows genetic variants in the FTO gene are associated with obesity-related traits. PLOS Genet. 2007;3(7):e115.

47. Meyre D, Delplanque J, Chevre JC, Lecoeur C, Lobbens S, Gallina S, et al. Genome-wide association study for early-onset and morbid adult obesity identifies three new risk loci in European populations. Nat Genet. 2009;41(2):157-9.

48. Scherag A, Dina C, Hinney A, Vatin V, Scherag S, Vogel Cl, et al. Two new loci for body-weight regulation identified in a joint analysis of genome-wide association studies for early-onset extreme obesity in French and German study groups. PLoS Genet. 2010;6(4):e1000916.
49. Cotsapas C, Speliotes EK, Hatoum IJ, Greenawalt DM, Dobrin R, Lum PY, et al. GIANT Consortium: common body mass index-associated variants confer risk of extreme obesity. Hum Mol Genet. 2009;18(18):3502-7.

50. Hinney A, Nguyen TT, Scherag A, Friedel S, Bronner G, Muller TD, et al. Genome wide association (GWA) study for early onset extreme obesity supports the role of fat mass and obesity associated gene (FTO) variants. PLoS One. 2007;2(12):e1361.

51. Toperoff G, Aran D, Kark JD, Rosenberg M, Dubnikov T, Nissan B, et al. Genome-wide survey reveals predisposing diabetes type 2-related DNA methylation variations in human peripheral blood. Hum Mol Genet. 2012;21(2):371-83.

52. Volkmar M, Dedeurwaerder S, Cunha DA, Ndlovu MN, Defrance M, Deplus R, et al. DNA methylation profiling identifies epigenetic dysregulation in pancreatic islets from type 2 diabetic patients. EMBO J. 2012;31(6):1405-26.

53. Ling C, Del Guerra S, Lupi R, Ronn T, Granhall C, Luthman $H$, et al. Epigenetic regulation of PPARGC1A in human type 2 diabetic islets and effect on insulin secretion. Diabetologia. 2008;51(4):615-22.

54. Bell CG, Finer S, Lindgren CM, Wilson GA, Rakyan VK. Integrated genetic and epigenetic analysis identifies haplotype-specific methylation in the FTO type 2 diabetes and obesity susceptibility locus. PLoS One. 2010;5(11):e14040.

55. Feinberg AP, Irizarry RA, Fradin D, Aryee MJ, Murakami $P$, Aspelund $T$, et al. Personalized epigenomic signatures that are stable over time and covary with body mass index. Sci Transl Med. 2010;2(49):ra67.

56. Relton CL, Groom A, St Pourcain B, Sayers AE, Swan DC, Embleton ND, et al. DNA methylation patterns in cord blood DNA and body size in childhood. PLoS One. 2012;7(3):e31821.

57. Ernst J, Kellis M. ChromHMM: automating chromatin-state discovery and characterization. Nat Methods. 2012;9(3):215-6.

58. Ernst J, Kheradpour P, Mikkelsen TS, Shoresh N, Ward LD, Epstein CB, et al. Mapping and analysis of chromatin state dynamics in nine human cell types. Nature. 2011:473(7345):43-9.

59. Subramanian A, Tamayo P, Mootha VK, Mukherjee S, Ebert BL, Gillette MA, et al. Gene set enrichment analysis: a knowledge-based approach for interpreting genome-wide expression profiles. Proc Natl Acad Sci U S A. 2005;102(43):15545-50.

60. Martino D, Loke YJ, Gordon L, Ollikainen M, Cruickshank MN, Saffery R, et al. Longitudinal, genome-scale analysis of DNA methylation in twins from birth to 18 months of age reveals rapid epigenetic change in early life and pair-specific effects of discordance. Genome Biol. 2013;14(5):R42.

61. Gordon L, Joo JE, Powell JE, Ollikainen M, Novakovic B, Li X, et al. Neonatal DNA methylation profile in human twins is specified by a complex interplay between intrauterine environmental and genetic factors, subject to tissuespecific influence. Genome Res. 2012;22(8):1395-406.

62. Dempster EL, Pidsley R, Schalkwyk LC, Owens S, Georgiades A, Kane F, et al. Disease-associated epigenetic changes in monozygotic twins discordant for schizophrenia and bipolar disorder. Hum Mol Genet. 2011;20(24):4786-96.

63. Dempster EL, Wong CC, Lester KJ, Burrage J, Gregory AM, Mill J, et al. Genome-wide methylomic analysis of monozygotic twins discordant for adolescent depression. Biol Psychiatry. 2014;76(12):977-83.

64. Bell JT, Loomis AK, Butcher LM, Gao F, Zhang B, Hyde CL, et al. Differential methylation of the TRPA1 promoter in pain sensitivity. Nat Commun. 2014;5:2978

65. Byrne EM, Carrillo-Roa T, Henders AK, Bowdler L, McRae AF, Heath AC, et al. Monozygotic twins affected with major depressive disorder have greater variance in methylation than their unaffected co-twin. Transl Psychiatry. 2013;3:e269.

66. Wong CC, Meaburn EL, Ronald A, Price TS, Jeffries AR, Schalkwyk LC, et al. Methylomic analysis of monozygotic twins discordant for autism spectrum disorder and related behavioural traits. Mol Psychiatry. 2014;19(4):495-503.

67. Ribel-Madsen R, Fraga MF, Jacobsen S, Bork-Jensen J, Lara E, Calvanese V, et al. Genome-wide analysis of DNA methylation differences in muscle and fat from monozygotic twins discordant for type 2 diabetes. PLoS One. 2012;7 (12):e51302.

68. Kotronen A, Yki-Jarvinen $\mathrm{H}$. Fatty liver: a novel component of the metabolic syndrome. Arterioscler Thromb Vasc Biol. 2008;28(1):27-38.

69. Stefan N, Kantartzis K, Machann J, Schick F, Thamer C, Rittig K, et al. Identification and characterization of metabolically benign obesity in humans. Arch Intern Med. 2008;168(15):1609-16.

70. Shen J, Wang S, Zhang YJ, Wu HC, Kibriya MG, Jasmine F, et al. Exploring genome-wide DNA methylation profiles altered in hepatocellular carcinoma using Infinium HumanMethylation 450 BeadChips. Epigenetics. 2013;8(1):34-43. 
71. Wang D, Liu X, Zhou Y, Xie H, Hong X, Tsai HJ, et al. Individual variation and longitudinal pattern of genome-wide DNA methylation from birth to the first two years of life. Epigenetics. 2012;7(6):594-605.

72. Hansen KD, Timp W, Bravo HC, Sabunciyan S, Langmead B, McDonald OG, et al. Increased methylation variation in epigenetic domains across cancer types. Nat Genet. 2011;43(8):768-75.

73. Grundberg E, Meduri E, Sandling JK, Hedman AK, Keildson S, Buil A, et al. Global analysis of DNA methylation variation in adipose tissue from twins reveals links to disease-associated variants in distal regulatory elements. Am J Hum Genet. 2013;93(5):876-90.

74. Koestler DC, Christensen B, Karagas MR, Marsit CJ, Langevin SM, Kelsey KT, et al. Blood-based profiles of DNA methylation predict the underlying distribution of cell types: a validation analysis. Epigenetics. 2013;8(8):816-26.

75. Langevin SM, Houseman EA, Accomando WP, Koestler DC, Christensen BC, Nelson $\mathrm{HH}$, et al. Leukocyte-adjusted epigenome-wide association studies of blood from solid tumor patients. Epigenetics. 2014;9(6):884-95.

76. Accomando WP, Wiencke JK, Houseman EA, Nelson HH, Kelsey KT Quantitative reconstruction of leukocyte subsets using DNA methylation. Genome Biol. 2014;15(3):R50. 2014-15-3-r50.

77. Michels KB, Binder AM, Dedeurwaerder S, Epstein CB, Greally JM, Gut I, et al. Recommendations for the design and analysis of epigenome-wide association studies. Nat Methods. 2013;10(10):949-55.

78. Reinius LE, Acevedo N, Joerink M, Pershagen G, Dahlen SE, Greco D, et al. Differential DNA methylation in purified human blood cells: implications for cell lineage and studies on disease susceptibility. PLoS One. 2012;7(7):e41361.

79. Liu Y, Aryee MJ, Padyukov L, Fallin MD, Hesselberg E, Runarsson A, et al. Epigenome-wide association data implicate DNA methylation as an intermediary of genetic risk in rheumatoid arthritis. Nat Biotechnol. 2013;31(2):142-7.

80. Jaffe $A E$, Irizarry RA. Accounting for cellular heterogeneity is critical in epigenomewide association studies. Genome Biol. 2014;15(2):R31. 2014-15-2-r31.

81. Mill J, Heijmans BT. From promises to practical strategies in epigenetic epidemiology. Nat Rev Genet. 2013;14(8):585-94.

82. Philibert RA, Plume JM, Gibbons FX, Brody GH, Beach SR. The impact of recent alcohol use on genome wide DNA methylation signatures. Front Genet. 2012;3:54

83. Kaprio J, Pulkkinen L, Rose RJ. Genetic and environmental factors in healthrelated behaviors: studies on Finnish twins and twin families. Twin Res. 2002;5(5):366-71.

84. Tyynismaa H, Raivio T, Hakkarainen A, Ortega-Alonso A, Lundbom N, Kaprio J, et al. Liver fat but not other adiposity measures influence circulating FGF21 levels in healthy young adult twins. J Clin Endocrinol Metab. 2011;96(2):E351-5.

85. Pietilainen $\mathrm{KH}$, Rissanen A, Laamanen M, Lindholm AK, Markkula $H$, Yki-Jarvinen $\mathrm{H}$, et al. Growth patterns in young adult monozygotic twin pairs discordant and concordant for obesity. Twin Res. 2004;7(5):421-9.

86. Mazess RB, Barden HS, Ohlrich ES. Skeletal and body-composition effects of anorexia nervosa. Am J Clin Nutr. 1990;52(3):438-41.

87. Lundbom J, Hakkarainen A, Fielding B, Soderlund S, Westerbacka J, Taskinen MR et al. Characterizing human adipose tissue lipids by long echo time 1H-MRS in vivo at 1.5 Tesla: validation by gas chromatography. NMR Biomed. 2010;23 (5):466-72.

88. Naressi A, Couturier C, Devos JM, Janssen M, Mangeat C, de Beer R, et al Java-based graphical user interface for the MRUI quantitation package. MAGMA. 2001:12(2-3):141-52.

89. Vanhamme L, van den Boogaart A, Van Huffel S. Improved method for accurate and efficient quantification of MRS data with use of prior knowledge. J Magn Reson. 1997;129(1):35-43.

90. Matthews DR, Hosker JP, Rudenski AS, Naylor BA, Treacher DF, Turner RC. Homeostasis model assessment: insulin resistance and beta-cell function from fasting plasma glucose and insulin concentrations in man. Diabetologia. 1985:28(7):412-9.

91. Bogl LH, Latvala A, Kaprio J, Sovijarvi O, Rissanen A, Pietilainen KH. An investigation into the relationship between soft tissue body composition and bone mineral density in a young adult twin sample. J Bone Miner Res. 2011:26(1):79-87.

92. Gentleman RC, Carey VJ, Bates DM, Bolstad B, Dettling M, Dudoit S, et al. Bioconductor: open software development for computational biology and bioinformatics. Genome Biol. 2004;5(10):R80.

93. Davis S, Du P, Bilke S, Triche TJ, Bootwalla M. Methylumi: handle Illumina methylation data. R package. 2014;v 2.12.

94. Teschendorff AE, Marabita F, Lechner M, Bartlett T, Tegner J, Gomez-Cabrero D, et al. A beta-mixture quantile normalization method for correcting probe design bias in Illumina Infinium 450 k DNA methylation data. Bioinformatics 2013;29(2):189-96.

95. Leek JT, Storey JD. Capturing heterogeneity in gene expression studies by surrogate variable analysis. PLoS Genet. 2007;3(9):1724-35.

96. Li H, Durbin R. Fast and accurate short read alignment with Burrows-Wheeler transform. Bioinformatics. 2009;25(14):1754-60.

97. Coolen MW, Statham AL, Gardiner-Garden M, Clark SJ. Genomic profiling of CpG methylation and allelic specificity using quantitative high-throughput mass spectrometry: critical evaluation and improvements. Nucleic Acids Res. 2007:35(18):e119.

98. Ollikainen M, Smith KR, Joo EJ, Ng HK, Andronikos R, Novakovic B, et al. DNA methylation analysis of multiple tissues from newborn twins reveals both genetic and intrauterine components to variation in the human neonatal epigenome. Hum Mol Genet. 2010;19(21):4176-88

99. Smyth G. Limma: linear models for microarray data. In: Gentleman R, Carey V, Dudoit S, Irizarry R, Huber W, editors. Bioinformatics and Computational Biology Solutions Using R and Bioconductor. New York: Springer; 2005. p. 397-420.

\section{Submit your next manuscript to BioMed Central and take full advantage of:}

- Convenient online submission

- Thorough peer review

- No space constraints or color figure charges

- Immediate publication on acceptance

- Inclusion in PubMed, CAS, Scopus and Google Scholar

- Research which is freely available for redistribution 